\title{
IS THE EARLY EVOLUTION OF LIFE RELATED TO THE DEVELOPMENT OF THE EARTH'S CORE?
}

\author{
By PROF. CARL SAGAN \\ Harvard University and Smithsonian Astrophysical Observatory, Cambridge, Mass.
}

$\mathrm{U}$ FFEN $^{1}$ has suggested that the surface magnetic ficld strength was vanishingly small some $3 \times 10^{9}$ years ago, as a consequence of the hypothesized slow growth of the fluid metallic core of the Earth; and that incidont charged particles from the Sun were not then deflected by the geomagnetic fiold. He proposes that a consequent intense flux of charged particles at the surface of tho Earth made the origin and evolution of life prior to $2.5 \times$ $10^{9}$ years ago impossiblo. He also suggests that, even in later epochs, the evolution of life was rendored difficult by the massive dumping of trapped particles from the Earth's Van Allen radiation belt, as the number of stable convective cells in the Earth's fluid core increased with time. It is the purpose of this communication to show that even if tho Earth's magnetic field was inconsequontial in Archaean times, the effect on the development of life on the planet Earth would not have been deleterious; and indeed, may have bcen salutary.

Biogenic organic matter and fossils of living organisms have been found in sodiments dated as old as $2 \cdot 0-2 \cdot 8 \times$ $10^{0}$ years $^{2-5}$. The existence of such relatively advanced organisms as colonial algae in this epoch points strongly to the likelihood that the origin of life occurred considerably earlior than $3 \times 10^{9}$ years ago, perhaps only a few times $10^{8}$ years after the formation of the Earth $4.5 \times 10^{9}$ years ago.

In the absence of the geomagnetic field, the surface of the Earth will not be bathed in the solar proton flux, because of absorption in the Earth's atmosphere. The solar proton flux and energy spectrum in interplanetary space near the Earth have been moasured by the Mariner 2 space-vehicle ${ }^{6}$. The proton energy, calculated on the assumption that all measured particles were protons, is characteristically botwoen 0.5 and $5 \mathrm{keV}$. A typical value of the proton flux is $2 \times 10^{8} \mathrm{~cm}^{-2} \mathrm{sec}^{-1}$. The proton flux in the energy-range above $10 \mathrm{koV}$ is expected to be relatively very small. The penetration depths of solar protons can be computed for any desired model atmosphere. The ranges of protons in air, in nitrogen, and in oxygen have been measured by Cook, Jones and Jorgensen ${ }^{7}$. For the purposes of the present discussion, there is no difference in the range in nitrogen and the range in oxygen.

The terrestrial atmosphere at the time of the origin of lif $\Theta$ was very likely roducing, and probably arose from the outgassing of the early mantle (see, for example, ref. 8). The exact proportions of molecular constituents in such an atmosphoro aro at present unknown, but substantial quantities of water, methane, nitrogen and ammonia are expected ${ }^{9}$. The proton range in such an atmosphere should be of the same order of magnitude as in air. In the present atmosphere of the Earth it is a simple mattor to compute the altitude reached by protons of given energios, incident vortically at the top of the atmosphere and travelling in an unbroken linear path. For l-keV protons, this altitude is about $125 \mathrm{~km}$; for $5-\mathrm{koV}$ protons, about $30 \mathrm{~km}$. Bocauso of the assumption of vertical incidence and rectilinear path, these will be maximum penetrations. Thus, were the present geomagnotic field turned off, the solur proton wind would in general not ponetrate into the troposphere. So long as the surface atmospheric pressure on the primitive Earth was as much a $10^{-2}$ atm., a solar proton wind of the contomporary onergy distribution would be nbsorbed in the atmosphere, and would not pose a hazard for the origin and evolution of life.

While there is some suspicion that the Earth's primitive atmosphere was entirely lost to space ${ }^{10,11}$, this is not the only possible interpretation of the data in question ${ }^{12}$; and, in any event, the airless epoch could only have occurred during - or possible even before-the formation of the Earth ${ }^{8}$. The question of the atmospheric pressure of the primitive Earth depends on tho unknown rate of outgassing in early times. But, for the large scale prebiological synthesis of organic matter in the primitive Earth, significant atmospheric pressures are required. Holland ${ }^{13}$ has suggested on geochemical grounds that the atmospheric pressure was greater than $10^{-2} \mathrm{~atm}$. throughout the interval between $4.5 \times 10^{\circ}$ years ago and the present. It therefore scems likely that had the solar proton flux approximately its present energy spectrum throughout geological timo, atmospheric attenuation would prevent any significant damage to pre-biological or biological processes on the primitive Earth, even in the absence of the geomagnotic field.

Similar conclusions apply to dumped charged particles from the Van Allen belts of much later epochs. Were the surface atmospherio pressure low in primitive times, some penetration of $\mathrm{MeV}$ particles to the surface can be oxpocted. But, in any event, organisms residing below the surface of the early waters would have been unaffected.

The penetration of the solar proton wind to the tropopause in primitive times does raise an interesting possibility concerning the origin of life. Since the initial experiments of Miller ${ }^{14}$, it has been clear that the bombardment of simulated primitive reducing atmospheres by charged particles is an officiont mechanism for the production of organic molecules of contemporary biological significanco (see, for example, ref. 15). A particle flux of $2 \times 18^{8}$ protons $\mathrm{cm}^{-2} \mathrm{sec}^{-1}$, each with energy in the $\mathrm{keV}$ range, corresponds to an energy flux approaching $1 \mathrm{erg} \mathrm{cm}^{-2}$ $\mathrm{sec}^{-1}$. This is a source of energy far inferior to ultra. violet light in primitive times ${ }^{16}$; but it is comparable with the estimated ${ }^{8}$ energy inputs to the primitive atmo. sphere from lightning, from corona discharges from pointed objects, and from radioactivity. Organic molecules produced by solar protons just below the tropopause would be convectively transported to the surface of the Earth. For this reason, experiments on pre-biological organic syntheses using $\mathrm{keV}$ protons as a source of energy may have some relevance to the origin of life.

${ }^{1}$ Uffen, R. J., Nature, 198, 143 (1963).

2 Barghoorn, E. S., and Tyler, S. A., Science, 147, 563 (1965).

- MacGregor, A. M., Trans. (Yeol. Soc. S. Africa, 43, 9 (1940).

4 Holmes, A., Nature, 178, 612 (1954).

s Marshall, C. G. A., May, I. W., and Perret, C. J., Science, 144, 290 (1964).

- Neugebauer, M., and Snyder, C. W., Jet Propulsion Lab. Tech. Mem. No. 33-111 (1962).

${ }^{7}$ Cook. C. J., Jones, E., and Jorgensen, T., Phys. Rev., 91, 1417 (1953).

- Sagan, C., in International Dictionary of Geophysics, edit. by Runcorn, S. K. Section I (Pergamon Press, in the press).

- Miller, S. L., and Urey, H. C., Science, 130, 245 (1959).

${ }^{10}$ Brown, H., in Atmospheres of the Earth and Planets, edit. by Kuiper, G. P. revised ed. (Univ. Chicago Press, 1952).

${ }^{11}$ Suess, H. E., J. Geol., 51, 600 (1949).

${ }^{12}$ Jokipil, J, B. Icarus, 3, 248 (1964).

${ }^{12}$ Holland, II. D., in The Origin and Evolution of Atmospheres and Oceans, edit. by Brancazio, P. J., and Cameron, A. G. W. (John Wiley, 2064).

"Miller, S. L., J. Amer. Chem. Soc., 77, 2351 (1955).

${ }^{15}$ Fox, S. W., ed., The Origins of P'rebiological Systems (Academic Press, $1965)$

${ }^{10}$ Sagan, C., in The Origins of Prebiolnurical Systems, edit. by Y'ox, S. W., 238 (Academic Press, 1965). 